\title{
The Impact of COVID-19 on Conspiracy Attitudes and Risk Perception in Italy: an Infodemiological Survey through Google Trends.
}

\author{
Alessandro Rovetta, \\ Mensana srls, Research and Disclosure Division, \\ Via Malta $12-25124$ Brescia, Italy. \\ Redeev Technological and Scientific Research, \\ Via San Pasquale a Chiaia 83, Naples, Italy. \\ Email: rovetta.mresearch@gmail.com \\ Phone: 39-3927112808 \\ ORCID: 0000-0002-4634-279X \\ Web of Science Researcher ID: AAT-9063-2020
}

\section{Funding}

This research did not receive any specific grant from funding agencies in the public, commercial, or not-for-profit sectors.

\section{Conflict of Interest}

None declared.

\section{Copyright statement}

This work is copyrighted (Patamu deposit number: 155163, CC BY-NC 4.0). The certain date of the generation of the author's proof is certified with time stamps and its validity is guaranteed pursuant to the 910/2014 EU eIDAS regulation for Digital Trust services. 


\begin{abstract}
Background: The novel coronavirus disease (COVID-19) caused the worst international crisis since World War II. Italy was one of the countries most affected by both the pandemic and the related infodemic. The success of anti-COVID-19 strategies and future public health policies in Italy cannot prescind from containment of fake news and divulgation of correct information.
\end{abstract}

Objective: The aim of this paper is to analyze the impact of COVID-19 on conspiracy attitudes and risk perception of Italian web users.

Methods: Google Trends was used to monitor users' web interest in specific topics, such as conspiracy hypotheses, vaccine side effects, and pollution/climate change. The keywords adopted to represent these topics were mined from Bufale.net - an Italian website specialized in detecting online hoaxes - and Google Trends suggestions (i.e., related topics and related queries). Relative search volumes of the timelapse 2016-2020 (pre-COVID-19) and 2020-2021 (post-COVID-19) were compared through percentage difference $\left(\Delta_{\%}\right)$ and Welch's t-test $(t)$. When data series were not stationary, other ad-hoc criteria were used. The trend slopes were assessed through Sen's Slope $(S S)$. The significance thresholds have been indicatively set at $P=.05$ and $t=1.9$.

Results: The COVID-19 pandemic drastically enforced Italian netizens' conspiracy attitudes $\left(\Delta_{\%} \in\right.$ $[60,288], t \in[6,12])$. The regional web interest towards conspiracy-related queries has increased and become more homogeneous compared to the pre-COVID-19 period $\left(\overline{R S V}=80 \pm 2.8, t_{\min }=\right.$ 1.8, $\Delta_{\text {min } \%}=+12.4$, $\min \Delta_{S D \%}=-25.8$ ). Besides, a growing trend in web interest in the infodemic YouTube channel "ByoBlu" has been highlighted. The web interest in fake news has increased more than that in anti-hoax services $\left(t_{1}=11.3\right.$ vs $t_{2}=4.5, \Delta_{1}=+157.6$ vs $\left.\Delta_{2}=+84.7\right)$. Equivalently, the web interest in vaccine side effects exceeded that in pollution/climate change $\left(S S_{v a c}=0.22, P<.001\right.$ vs $\left.S S_{p o l}=0.05, P<.001, \Delta_{\%}=+296.4\right)$.

Conclusions: COVID-19 has given a significant boost to online conspiracy attitudes in Italy. In particular, the average web interest in conspiracy hypotheses has increased and become more uniform across regions. The pandemic accelerated an already growing trend in users' interest towards some fake news sources, including the 500,000 subscribers YouTube channel "ByoBlu" (canceled for disinformation in March 2021). The risk perception related to COVID-19 vaccines has been so distorted that vaccine side effects-related queries outweighed those relating to pollution and climate change, which are much more urgent issues. Based on these findings, it is necessary that the Italian authorities implement more effective infoveillance systems and communication by the mass media is less sensationalistic and more consistent with the available scientific evidence. In this context, Google Trends can be used to monitor the users' response to specific infodemiological countermeasures. Further research is needed to understand the psychological mechanisms that regulate risk perception.

Keywords: COVID-19, fake news, Google Trends, infodemiology, Italy, risk perception 


\section{Introduction}

The coronavirus disease 2019 (abbreviated in COVID-19) was responsible for one of the dramatic global crises after World War II. To date (April 24, 2021), the official global toll is 144 million cases and 3.1 million deaths [1]. Such a pandemic has also triggered a vast infodemic capable of seriously damaging the economy and sanitary system of many countries, as well as favoring the spread of the novel coronavirus itself [2]. Specifically, an infodemic is defined as an excessive amount of unfiltered information concerning a problem such that the solution is made more difficult [3]. As reported by the World Health Organization (WHO), this phenomenon can intensify or lengthen outbreaks. For this reason, a huge infoveillance effort has been made to study the information circulating on the web and contain the spread of fake news [4]. In this context, 132 nations worldwide signed a document to guarantee their commitment to the battle against disinformation and misinformation [5]. On the operational level, infodemic management takes place through 4 key points: i) listening to community concerns and questions, ii) promoting understanding of risk and health expert advice, iii) building resilience to misinformation, iv) engaging and empowering communities to take positive action [2]. This paper focuses on points ii) and iii) as concerns Italy, one of the nations most affected by COVID19 [1]. In particular, this study aims to analyze and quantify the impact of COVID-19 on Italian netizens' risk perception and conspiracy attitudes through Google Trends, an infoveillance tool provided by Google ${ }^{\mathrm{TM}}$ that returns users' web interest in specific topics in the form of normalized values called "relative search volumes" (RSVs) [6]. Google Trends has been exploited extensively in the scientific community to conduct infodemiological, medical, psychological, economic, and even epidemiological studies [7-12]. Indeed, although the media can influence users' web searches [13], Google Trends provides valuable details on the dynamics of users' online interests (including the influence of the media on collective thinking) $[14,15]$.

At present, the success of the vaccination campaign is crucial in the fight against COVID-19 [16, 17]. Conspiracy hypotheses, inadequate risk perception, and unjustified fears have already undermined non-pharmacological containment measures and can reduce the effectiveness of pharmacological ones [18]. Furthermore, these factors can compromise the management of equally serious problems such as pollution and climate change (often linked to COVID-19 incidence and mortality) [19-21]. Therefore, such a scenario requires careful surveillance of the online information flow as well as thoughtful communication. As we will show in this research, Google Trends can help achieve this goal. 


\section{Methods}

\section{Data collection}

For each topic appropriate keywords were selected as explained in the following subsections. Each keyword was searched on Google Trends under the category "all categories". The timelapse was set at five years (April 21, 2016 - April 21, 2021). Only the most relevant queries were included in the results (i.e. $\overline{R S V}>1$ ). All keywords were collected for at least 7 consecutive days in order to highlight potential anomalies and significant variations [22].

\section{- Pre-existing fake news}

Pre-existing fake news and disinformation channels were mined from the specialized anti-hoaxes website "Bufale.net" [23]. Four keywords that can represent the main conspiracy-related web interests on Google Trends were identified: "cospirazione + nuovo ordine mondiale + complotto" (conspiracy + new world order + plot), "byoblu" (a 500,000 subscribers YouTube channel canceled in March 2021 for disinformation), "Maurizio Blondet" (an Italian journalist who supports conspiracy hypotheses), and "luogocomune" (a Facebook page sharing conspiracy hypotheses).

\section{- Risk perception}

RSVs of the query "fake news + bufale + notizie false" (fake news + hoaxes + false news) and the previous queries (Pre-existing fake news) were compared. By doing so, it was possible to observe the impact of the pandemic on web interest in anti-hoax services and hoaxes themselves. The selection of the queries with the highest RSVs was conducted by consulting related topics and related queries provided by Google Trends. The same procedure was carried out for the queries "vaccini effetti collaterali + vaccino effetti collaterali" (vaccine side effects + vaccine side effects) and "inquinamento + cambiamento climatico" (pollution + climate change) queries. In this way, it was possible to evaluate the web interest in two very distant topics in terms of health risk and incidence [24-26].

Statistical Analysis

\section{- Welch's t-test}

Welch's t-test was used independently of the dataset distribution thanks to the central limit theorem ( $N>30$, with $N$ number of measures). The difference between the two mean values was considered significant indicatively when $t>1.9$.

\section{- Percentage change}

The percentage change $\Delta_{\%}$ was calculated through the formula $\left[y\left(T_{2}\right)-x\left(T_{1}\right)\right] / x\left(T_{1}\right) \cdot 100$, where $T_{i}$ is a specific timelapse.

\section{- Mean values}

All mean values were calculated using the standard arithmetic mean and presented through the notation $A V \pm S E M$, where $S E M$ represents the standard error of the mean. When $N<30$, the Shapiro-Wilk test was performed to assess the goodness of the mean value as a statistical measure. 


\section{- Data series analysis}

All data series were graphed. To signal the presence/absence of trends, augmented Dickey-Fuller $(\mathrm{ADF})$ and Mann-Kendall + Sen's Slope $(\mathrm{MK}+\mathrm{SS})$ tests were adopted. The same tests were used to evaluate datasets stationarity. Calculations were performed with Microsoft Excel 2021 software through the Real-Statistics 2021 package (Supplementary File 1). The optimal lag was determined using the Schwert criterion.

\section{- Data series comparison}

To provide a quantitative estimate of the effect of COVID-19 on web queries, RSV trends over the last five years (21 April 2016 - 21 April 2021) were analyzed. As shown in a previous paper, Italian netizens showed a marked interest in the COVID-19 pandemic only when this became a direct national problem [27]. Therefore, the timelapse "21 April 2016 - 16 February 2020" (period 1) and "16 February 2020 - 21 April 2021" (period 2) were compared. When period 1 turned out to be stationary or contained a negative trend, $t$ and $\Delta_{\%}$ have been calculated. When period 1 contained a stationary positive trend, the trend slopes of period 1 and a specific subperiod "16 February 2020 - x" of period 2 were compared by $\Delta_{\%}$; such a subperiod was selected by observing the region of the graph in which a possible positive level-shift occurred. Period 1 data were then linearly, quadratically, or sigmoidally interpolated, depending on which monotone function minimized the statistical errors. Period 2 data were interpolated through a polynomial function of 9 th degree. Finally, $\Delta_{\%}$ was calculated between the areas subtended by the two curves after February 16, $2020\left(\Delta A_{\%}\right)$. These were calculated using a definite integral between weeks 201 and 264. When period 1 contained a positive level-shift but was piecewise quasi-stationary, $t$ and $\Delta_{\%}$ were calculated considering only the last quasi-stationary subperiod.

\section{- P-values}

P-values were used as graded measures of evidence against the null hypothesis. An indicative threshold has been set at $P=.05$; however, exact P-values for ADF and MK+SS were reported in Supplementary File 1. 


\section{Results}

Web interest in pre-existing fake news

The impact of COVID-19 on conspiracy-related queries RSVs was evident (Figure 1): in particular, $\Delta_{1 \%}=+102.5, t_{1}=6.3 ; \Delta_{2 \%}=+288.2, t_{2}=11.5 ; \Delta A_{3 \%}=+10.2 ; \Delta_{4 \%}=+60.6, t_{4}=6.2$.

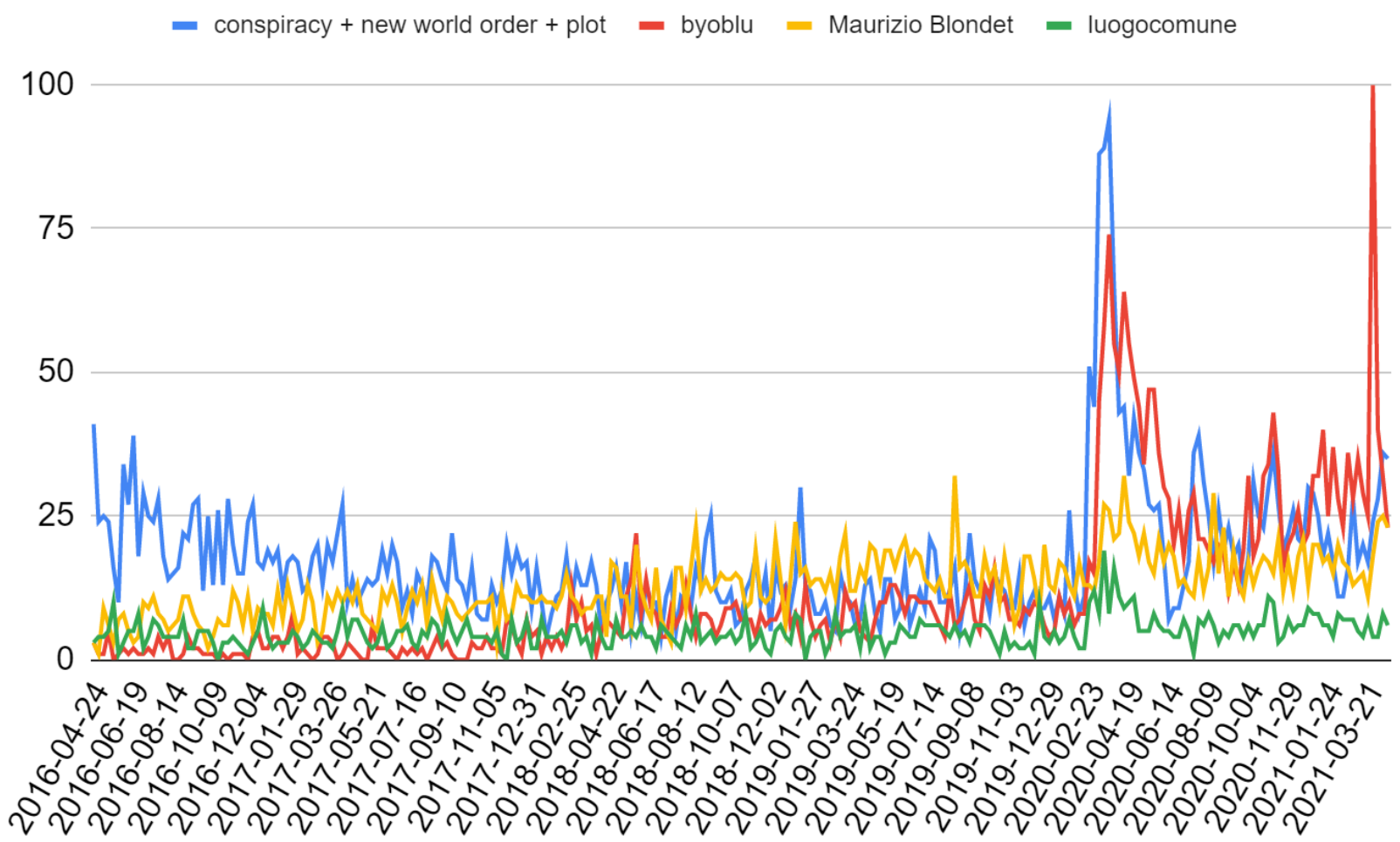

Figure 1. Conspiracy-related web relative search volumes (RSV) from April 21, 2016, to April 21, 2021 (Italy). Y-axis = RSV.

It is relevant that COVID-19 national outbreak has influenced the RSV trend even after the end of the first lockdown (May 2020). Indeed, Figure 1 shows a permanent level shift for all the investigated web queries.

Regional interest in conspiracy-related keyword 1 decreased on average during 2016-2020 timelapse, from $71 \pm 4.2$ to $52 \pm 4.1$ (Table 1). From 2020 to 2021 , the increase in RSV was manifest and common to all regions $\left(\overline{R S V}=80 \pm 2.8, t_{\min }=1.8, \Delta_{\min \%}=+12.4 ; t_{\max }=5.7, \Delta_{\max \%}=\right.$ +54.6). Over the period 2016-2020, the percentage standard deviation varied in the range $[22.1,32.6]$, while it reached an absolute minimum of 14.4 during the COVID-19 pandemic. This fact shows that web interest in conspiracies has also become more homogeneous across regions. No correlation was sought as data was subject to a strong dependence on the day of collection [25]; however, the mean values and standard deviations never changed significantly $\left(t_{\max }=0.4\right)$. 


\begin{tabular}{|c|c|c|c|c|c|}
\hline Region & 2016-2017 & 2017-2018 & 2018-2019 & 2019-2020 & $2020-2021$ \\
\hline Abruzzo & 100 & 76 & 38 & 53 & 67 \\
\hline \multicolumn{6}{|l|}{ Basilicata } \\
\hline Calabria & 48 & 61 & 80 & 27 & 78 \\
\hline Campania & 62 & 69 & 59 & 44 & 75 \\
\hline Emilia-Romagna & 74 & 70 & 77 & 68 & 80 \\
\hline Friuli-Venezia Giulia & 91 & 68 & 39 & 100 & 100 \\
\hline Lazio & 64 & 85 & 74 & 51 & 84 \\
\hline Liguria & 81 & 100 & 52 & 69 & 89 \\
\hline Lombardia & 85 & 75 & 63 & 43 & 86 \\
\hline Marche & 73 & 68 & 64 & 62 & 91 \\
\hline \multicolumn{6}{|l|}{ Molise } \\
\hline Piemonte & 56 & 75 & 94 & 58 & 88 \\
\hline Puglia & 70 & 78 & 45 & 49 & 67 \\
\hline Sardegna & 78 & 36 & 100 & 41 & 95 \\
\hline Sicilia & 80 & 77 & 62 & 43 & 69 \\
\hline Toscana & 84 & 75 & 72 & 44 & 80 \\
\hline Trentino-Alto Adige & 26 & 41 & 27 & 29 & 54 \\
\hline Umbria & 70 & 82 & 87 & 49 & 77 \\
\hline \multicolumn{6}{|l|}{ Valle d'Aosta } \\
\hline Veneto & 72 & 54 & 72 & 52 & 84 \\
\hline AV & 71,4 & 70,0 & 65,0 & 51,9 & 80,2 \\
\hline SD & 17,2 & 15,5 & 20,3 & 16,9 & 11,5 \\
\hline SD\% & 24,1 & 22,1 & 31,2 & 32,6 & 14,4 \\
\hline SEM & 4,2 & 3,8 & 4,9 & 4,1 & 2,8 \\
\hline SEM\% & 5,9 & 5,4 & 7,6 & 7,9 & 3,5 \\
\hline Shapiro-Wilk P & $1,50 \mathrm{E}-04$ & 0,18 & 0,97 & 0,05 & 0,93 \\
\hline
\end{tabular}

Table 1. "Conspiracy + New World Order + Plot" web relative search volumes (RSV) year by year from 2016 to 2021 (Italian regions). $\mathrm{AV}=$ average value, $\mathrm{SEM}=$ standard error of the mean. 
On the contrary, the web interest in the ByoBlu disinformation channel has always been compatible during $\quad 2016-2021 \quad\left(t \in[-1.3,1.1], \Delta_{\%} \in[-16.3,+21.8], t_{20-21}=-0.1, \Delta_{20-21}=-1.0\right.$, Supplementary File 1). Since Figure 1 witnesses a substantial increase in national searches, it is evident that the query "byoblu" was searched more in some regions than others. By analyzing the regional trends one by one, it can be observed that the "byoblu" web interest has increased over time except for Basilicata and Molise (Figure 2). Although a growing trend was already present, the novel coronavirus seems to have strongly impacted RSVs in Campania $\left(\Delta_{20-21 \%}=+93.3\right.$ vs $\Delta_{19-20 \%}=$ $+63.8)$, Friuli-Venezia Giulia $\left(\Delta_{20-21 \%}=+187.6\right.$ vs $\left.\Delta_{19-20 \%}=+59.0\right)$, Lazio $\left(\Delta_{20-21 \%}=\right.$ +95.7 vs $\left.\Delta_{19-20 \%}=+15.8\right)$, Trentino-Alto Adige $\left(\Delta_{20-21 \%}=+173.2\right.$ vs $\left.\Delta_{19-20 \%}=+4.5\right)$, and Valle d'Aosta $\left(\Delta_{20-21 \%}=+199.2\right.$ vs $\left.\Delta_{19-20 \%}=+86.2\right)$.

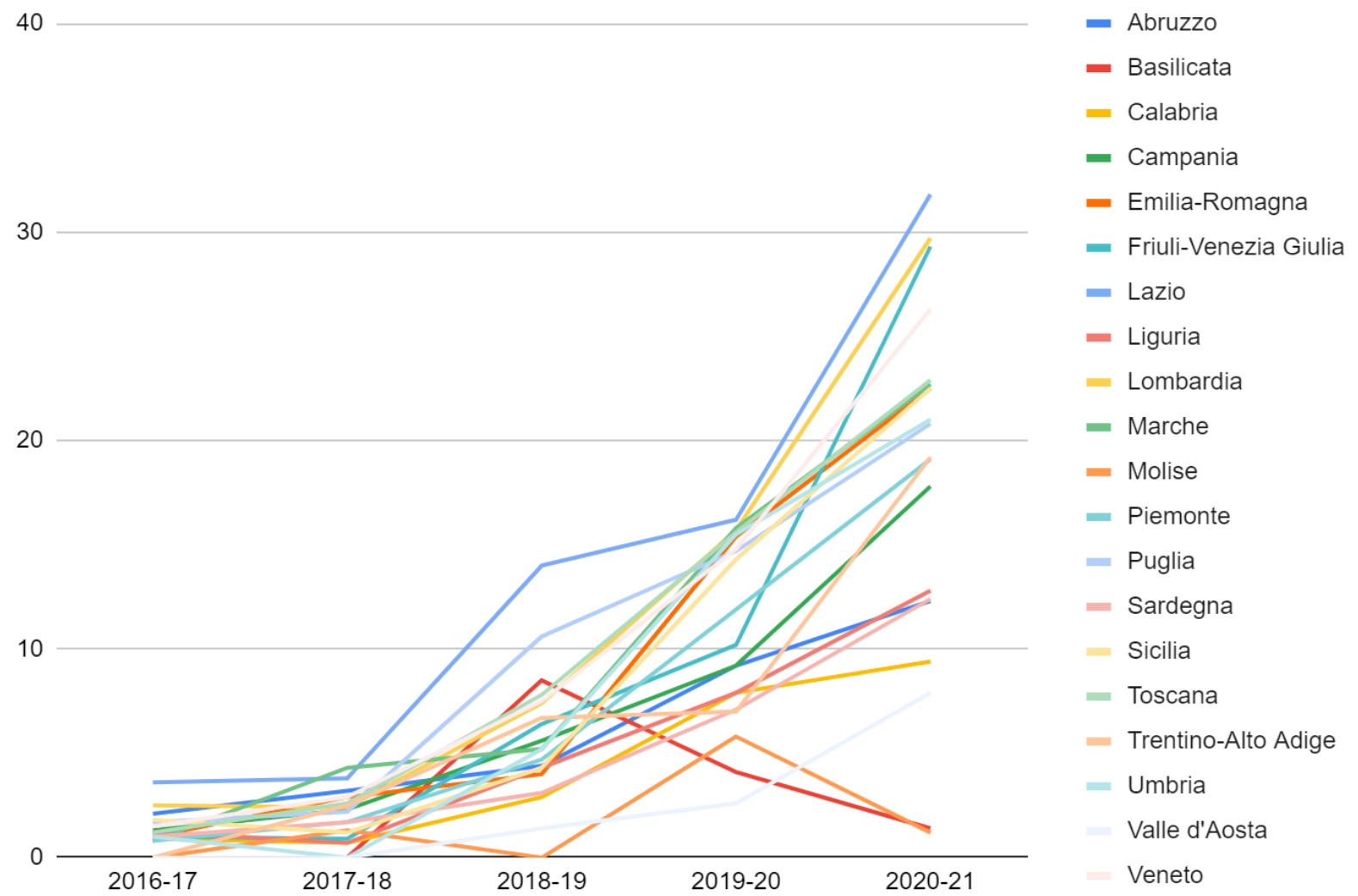

Figure 2. Web interest of the Italian regions in the "byoblu" query year by year from 2016 to 2021. Y-axis = average relative search volume.

\section{Risk perception}

A part of the users seemed aware of the high number of fake news on COVID-19 circulating on the web and tried to limit its effects by relying on anti-hoax websites (Figure 3, next page). Nevertheless, the impact of COVID-19 was more incisive for conspiracy hypotheses $\left(t_{1}=11.3 v s t_{2}=4.5\right.$, $\Delta_{1}=+157.6$ vs $\Delta_{2}=+84.7$ ), so much so that it is possible to observe a greater level-shift in the trend of infodemic web queries. This worsening was homogeneous on a national scale (Figure 4). 


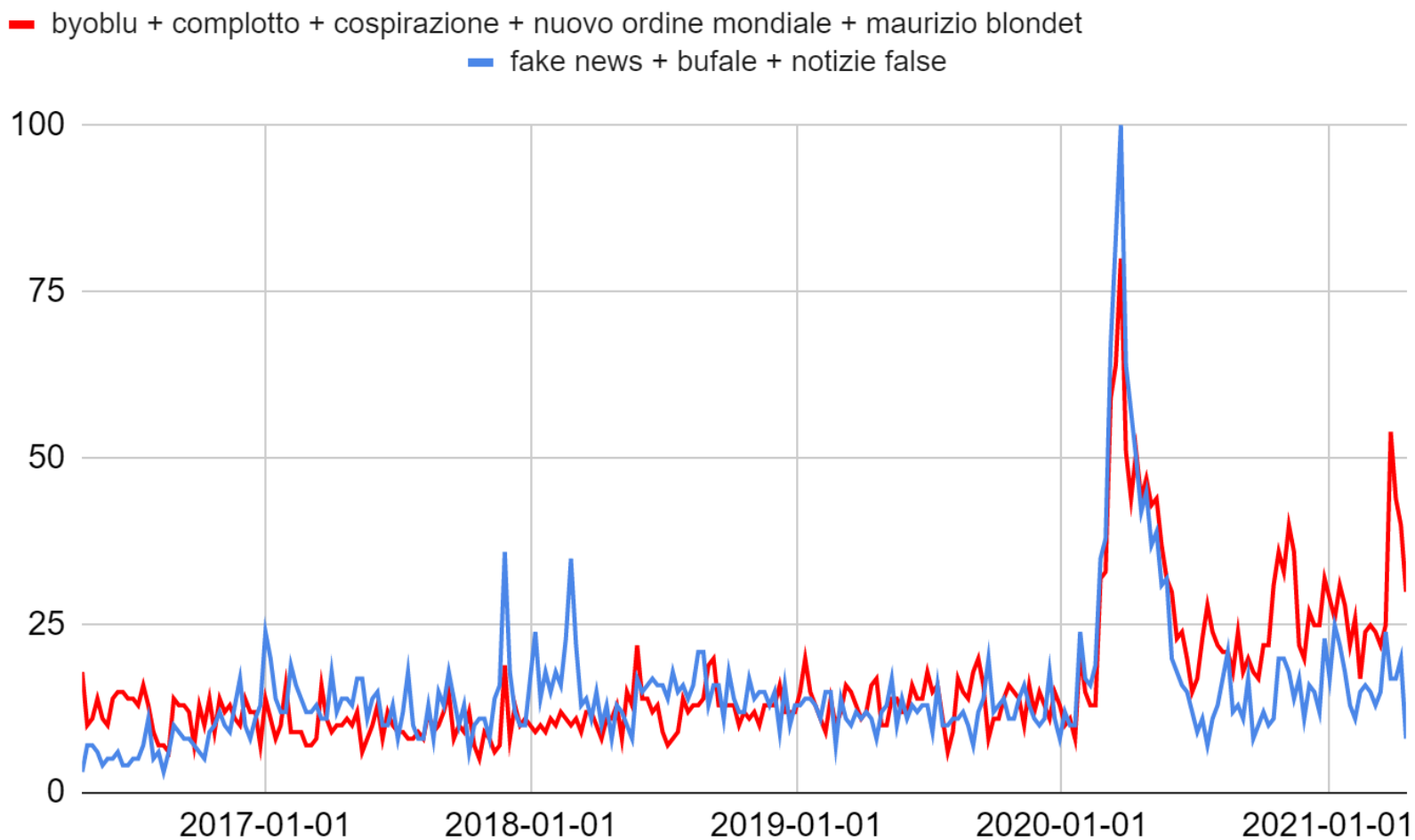

Figure 3. Comparison between the web interest in conspiracy hypotheses and anti-hoax services from 2016 to 2021 . Yaxis $=$ relative search volumes.
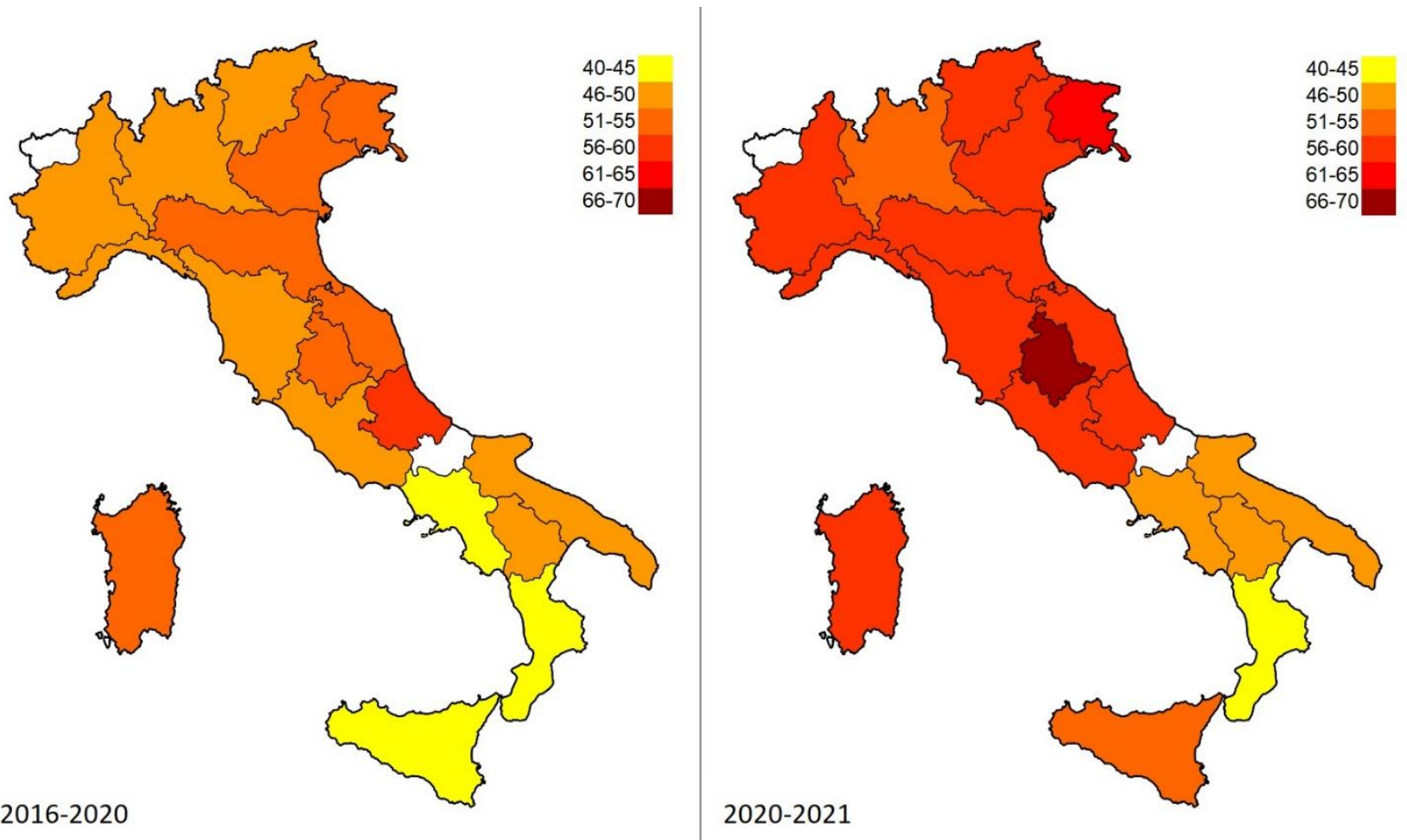

Figure 4. Heatmap of the relationship between web interest in conspiracy hypotheses and anti-hoax services: comparison 2016-2020 and 2020-2021. The index shows the percentage of infodemic queries (e.g. 70 means $70 \%$ conspiracy-related queries vs $30 \%$ anti-hoax-related queries). 
With the announcement of the discovery of COVID-19 vaccines, web interest in side effects immediately soared $\left(t=10.3, \Delta_{\%}=+905.2\right.$ from October 2020 to April 2021). Although health authorities report rare side effects of adenoviral vector vaccines only, web interest in this topic has exceeded that in pollution and climate change $\left(S S_{v a c}=1.2, P_{M K}<.001\right.$ vs $S S_{p o l}=0.81, P_{M K}<$ $.001, \Delta_{\%}=+44.0$, Figure 4 ), which are much more urgent issues. Pollution and climate change effects-related query returned negligible RSVs.

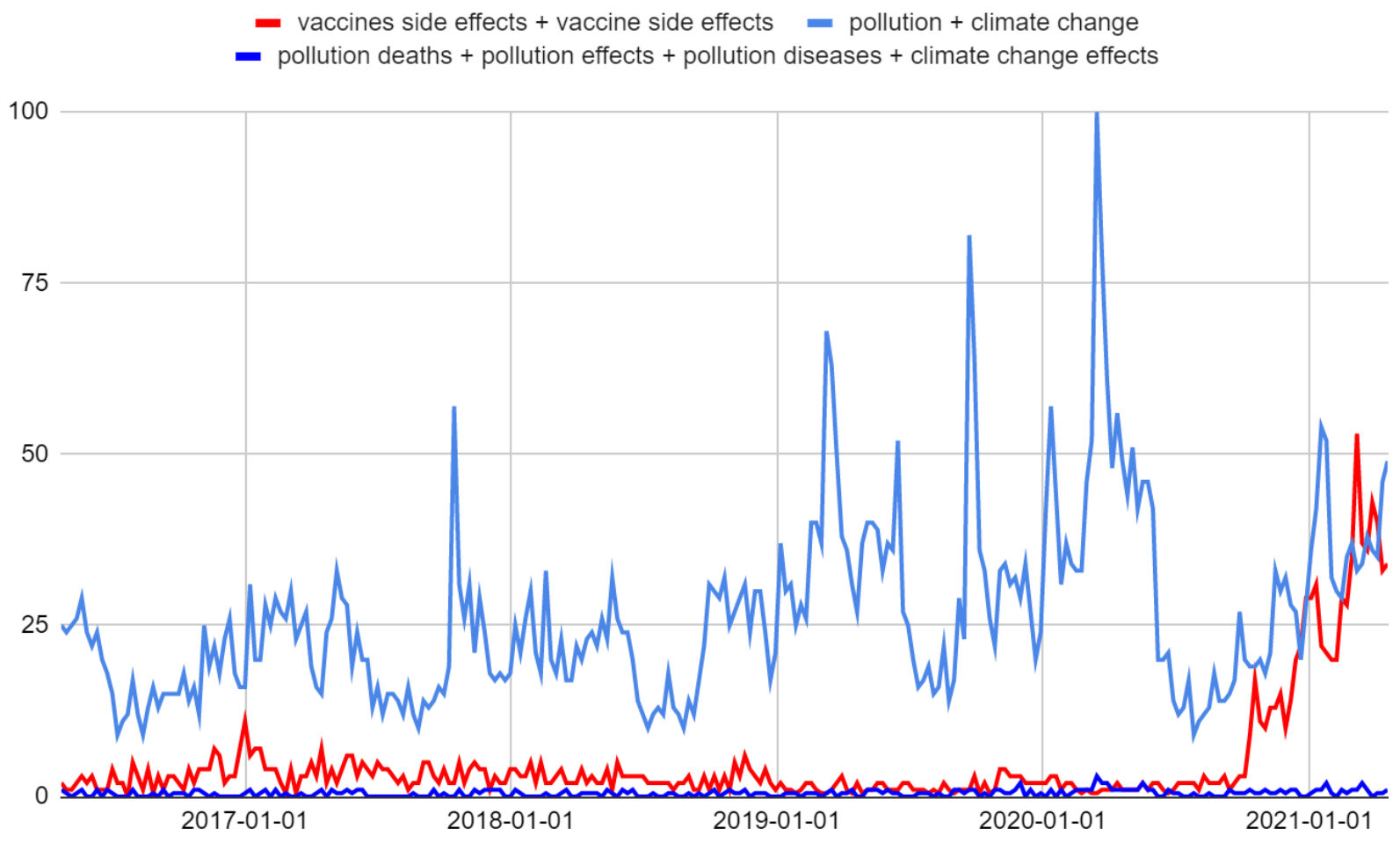

Figure 5. Web interest in vaccines side effects and pollution/climate change from 2016 to 2021.

When considering vaccines names-related queries, the gap between the RSVs further widens $\left(S S_{v a c}=0.22, P_{M K}<.001\right.$ vs $\left.S S_{p o l}=0.05, P_{M K}<.001, \Delta_{\%}=+296.4\right)$. As observable in Figure 6 , the risk perception in vaccines has surpassed that in pollution and climate change in a homogeneous way throughout Italy (Figure 6, next page). 

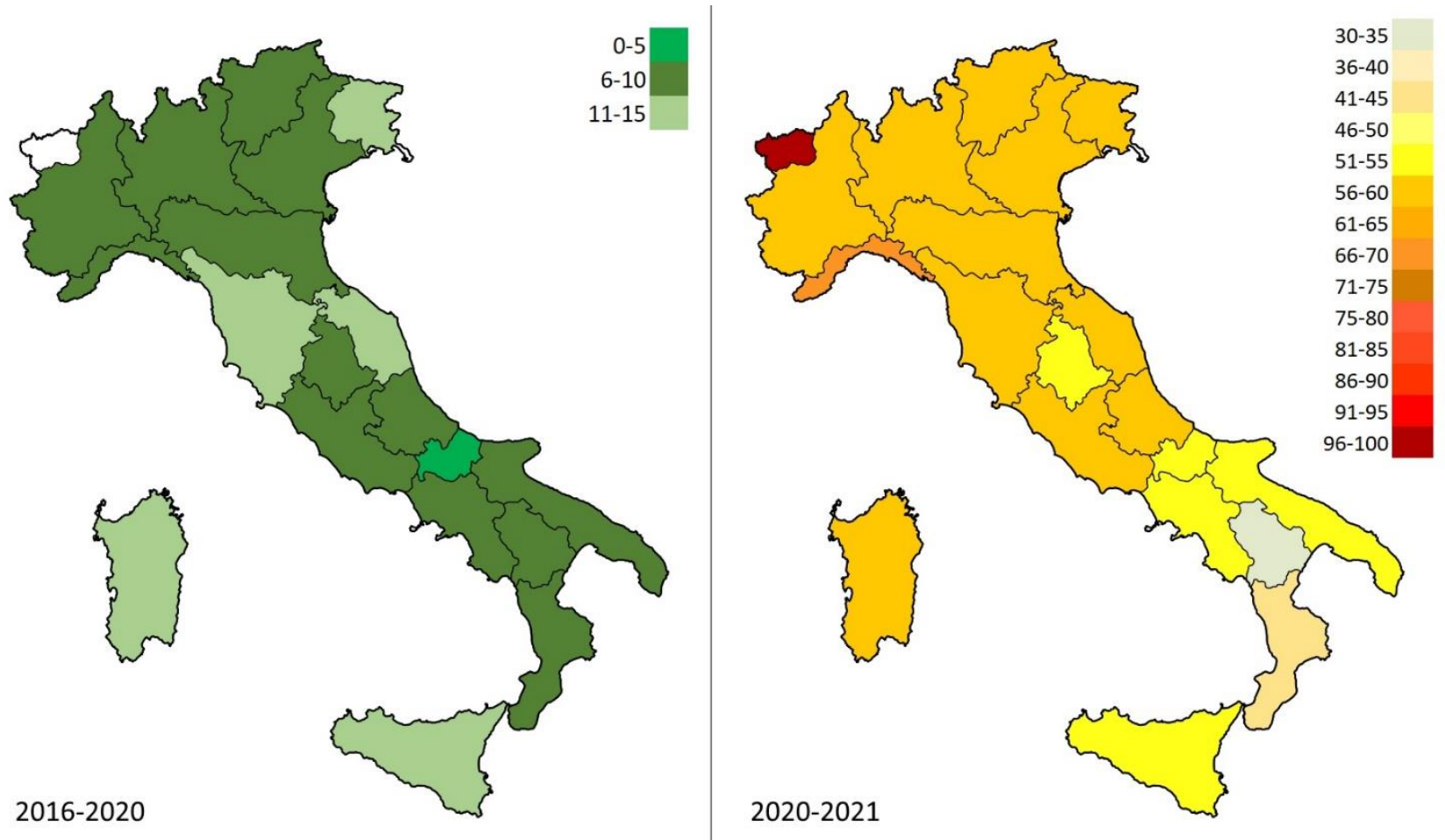

Figure 6. Comparison between the web interest in vaccines and pollution/climate change. The index shows the percentage of vaccine-related queries (e.g. 70 means $70 \%$ vaccine side effects queries vs $30 \%$ pollution/climate change-related queries). 


\section{Discussion}

\section{Principal Findings}

To the best of the author's knowledge, this is the first study to investigate the impact of COVID-19 on pre-existing fake news and the risk perception of Italian web users. These findings show that the pandemic - understood as a set of different situations such as health crisis, economic crisis, lockdown, disease, infodemic - has significantly increased the phenomenon of conspiracy and interest in it. This influence caused not only a marked initial growth of relative search volume (RSV) during the first lockdown (March-May 2020) but also generated a pronounced level-shift in web interest that has persisted until nowadays. The regional web interest in the conspiracy hypotheses in the pre-COVID19 2016-2020 period had assumed a clear negative trend and was more noticeable in some areas than in others. However, with the advent of the novel coronavirus, interest has increased to reach the highest value in the last five years, becoming even more homogeneous across regions. Due to the high dependence of the RSV on the day of gathering, it was not possible to search for correlations with the regional number of COVID-19 cases; nevertheless, the mean values and the variance of the sample have always remained similar. On the contrary, analyzing the data year by year, no change in the average interest in the infodemic YouTube channel "ByoBlu" (which had over 500,000 subscribers) was observed between the regions. Since a strong increase was highlighted nationwide, some regions must have contributed far more than others to the jump in total RSV. Specifically, as shown in Figure 2, Campania, Lazio, Friuli-Venezia Giulia, Trentino-Alto Adige, and Valle d'Aosta experienced a much higher increase than the other regions. Moreover, a growing trend in RSV during the last five years characterized all regions except Basilicata and Molise. Finally, web interest in fake news sources has increased more than that in anti-hoax services. These results are not to be underestimated: indeed, the Ministry of Health, various online platforms such as YouTube and Twitter, and social networks such as Facebook and Instagram have declared war without borders against the rampant infodemic. Specifically, under each video relating to the pandemic, YouTube has affixed a warning bar that offers users the opportunity to read the latest COVID-19 news on the Ministry of Health official website (complete with a button to access it). A similar procedure has been adopted by Facebook and Instagram (Figure 7, next page). All these companies have banned accounts and channels protagonists of the fake news spread, including ByoBlu [28-32]. This approach is partially consistent with the procedure proposed by the WHO to deal with the infodemic but was not sufficient to avoid a boost in disinformation in Italy. Among the problems that have undermined the effectiveness of these strategies, there is the resonance given by newspapers and television channels to unreliable or misleading information [33-36]. Beyond the mere disinformation contribution, this can foster distrust towards mass media, making the information campaign even more complex during times of crisis [37]. Furthermore, despite all the countermeasures adopted, social networks and messaging applications such as WhatsApp are a constant vehicle of fake news [33, 34, 37]. 


\section{COVID-19}

Ministero della Salute: ricevi notizie su COVID-19.

G Scopri altre risorse su Google $[0$

f Visita il Centro informazioni sul COVID-19 per risorse sui vaccini. Ottieni informazioni sui vaccini informazioni sul COVID-19.

Figure 7. YouTube, Facebook, and Instagram COVID-19 informative bars (Italian language).

Alongside this, the influence of newspapers and television news on the risk perception on antiCOVID-19 vaccines was evident. Although the trend has been on the rise since early October 2020, the headlines of online, printed, and television news publications have often been the subject of criticism from the scientific community as sensationalistic and far from scientific evidence [38-40]. Distrust of vaccines is a growing problem that raises a serious question of public health [41-43]. Although most vaccines-related fake news circulates on social networks, the national mass media must attend to the evidence presented in the scientific literature with appropriate and thoughtful language. In particular, the effect of deliberately misleading titles linked to secondary aspects of the article can have serious consequences [44]. In such an intricate scenario, the web interest in vaccine side effects has overtaken that in pollution and climate change. Notwithstanding that the author of this paper loudly supports the pharmacovigilance process and is aware of the existence of numerous studies on the possible causal link between adenoviral vector COVID-19 vaccines and thrombotic events [45-47], it is necessary to consider that pollution and climate change constitute today one of the major global threats, claiming millions of victims every year [25, 48]. Since Janssen and Vaxzevria vaccines have very rare side effects [26, 48-51], it is reasonable to conclude that the risk perception of Italian users is distorted and disconnected from the real dangers that menace it. This is even more true when considering the incidence of COVID-19 itself in this type of event $[52,53]$.

\section{Limitations}

There are no guarantees that Google Trends is sufficient to investigate the totality of the interests of the Italian public. Furthermore, it is not certain that the keywords used in this research include all the terms related to the topics investigated.

\section{Conclusions}

COVID-19 has given a significant boost to online conspiracy attitudes in Italy. In particular, the average web interest in conspiracy hypotheses has increased and become more uniform across 
regions. The pandemic accelerated an already growing trend in users' interest towards some fake news sources, including the 500,000 subscribers YouTube channel "ByoBlu" (canceled for disinformation in March 2021). The risk perception related to COVID-19 vaccines has been so distorted that vaccine side effects-related queries outweighed those relating to pollution and climate change, which are much more urgent issues. Based on these findings, it is necessary that the Italian authorities implement more effective infoveillance systems and communication by the mass media is less sensationalistic and more consistent with the available scientific evidence. In this context, Google Trends can be used to monitor the users' response to specific infodemiological countermeasures. Further research is needed to understand the psychological mechanisms that regulate risk perception. 


\section{References}

1. World Health Organization. WHO Coronavirus (COVID-19) Dashboard. 2020. [Accessed: 2021, Apr 24]. URL: https://covid19.who.int/

2. World Health Organization. The COVID-19 Infodemic. 2020. [Accessed: 2021, Apr 24]. URL: https://www.who.int/health-topics/infodemic/the-covid-19-infodemic

3. Eysenbach G. Infodemiology and Infoveillance: Framework for an Emerging Set of Public Health Informatics Methods to Analyze Search, Communication and Publication Behavior on the Internet J Med Internet Res 2009;11(1):e11. doi: 10.2196/jmir.1157, PMID: 19329408. URL: https://www.jmir.org/2009/1/e11.

4. Tsao SF, Chen H, Tisseverasinghe T, Yang Y, Li L, Butt ZA. What social media told us in the time of COVID-19: a scoping review. Lancet Digit Health. 2021 Mar;3(3):e175-e194. doi: 10.1016/S2589-7500(20)30315-0, PMID: 33518503. URL: https://pubmed.ncbi.nlm.nih.gov/33518503/

5. France Organisation des Nations Unies (ONU). Cross-Regional Statement on "Infodemic" in the Context of COVID-19. 2020. [Accessed: 2021, Apr 24]. URL: https://onu.delegfrance.org/IMG/pdf/crossregional_statement_on_infodemic_final_with_all_endorsements.pdf

6. Google Support. FAQ about Google Trends data. [Accessed: 2021, Apr 24]. URL: https://support.google.com/trends/answer/4365533?hl=en

7. Sousa-Pinto B, Anto A, Czarlewski W, Anto JM, Fonseca JA, Bousquet J. Assessment of the Impact of Media Coverage on COVID-19-Related Google Trends Data: Infodemiology Study. J Med Internet Res 2020;22(8):e19611. doi: 10.2196/19611, PMID: 32530816. URL: https://www.jmir.org/2020/8/e19611/

8. Nuti SV, Wayda B, Ranasinghe I, Wang S, Dreyer RP, Chen SI, Murugiah K. The use of google trends in health care research: a systematic review. PLoS One. 2014 Oct 22;9(10):e109583. doi: 10.1371/journal.pone.0109583, PMID: 25337815. URL: https://www.ncbi.nlm.nih.gov/pmc/articles/PMC4215636/

9. Saladino V, Algeri D, Auriemma V. The Psychological and Social Impact of Covid-19: New Perspectives of Well-Being. Front Psychol. 2020 Oct 2;11:577684. doi: 10.3389/fpsyg.2020.577684, PMID: $33132986 . \quad$ URL: https://www.ncbi.nlm.nih.gov/pmc/articles/PMC7561673/

10. Asgari Mehrabadi M, Dutt N, Rahmani AM The Causality Inference of Public Interest in Restaurants and Bars on Daily COVID-19 Cases in the United States: Google Trends Analysis JMIR Public Health Surveill 2021;7(4):e22880. doi: 10.2196/22880, PMID: 33690143. PMID: https://publichealth.jmir.org/2021/4/e22880/ 
11. Effenberger M, Kronbichler A, Shin JI, Mayer G, Tilg H, Perco P. Association of the COVID19 pandemic with Internet Search Volumes: A Google TrendsTM Analysis. Int J Infect Dis. 2020 Jun;95:192-197. doi: 10.1016/j.ijid.2020.04.033, PMID: 32305520. URL: https://pubmed.ncbi.nlm.nih.gov/32305520/

12. Jimenez AJ, Estevez-Reboredo RM, Santed MA, Ramos V. COVID-19 Symptom-Related Google Searches and Local COVID-19 Incidence in Spain: Correlational Study J Med Internet Res 2020;22(12):e23518. doi: 10.2196/23518, PMID: 33156803. URL: https://www.jmir.org/2020/12/e23518/

13. Cervellin G, Comelli I, Lippi G. Is Google Trends a reliable tool for digital epidemiology? Insights from different clinical settings. J Epidemiol Glob Health. 2017 Sep;7(3):185-189. doi: 10.1016/j.jegh.2017.06.001. PMID: $28756828 . \quad$ URL: https://www.ncbi.nlm.nih.gov/pmc/articles/PMC7320449/

14. Seung-Pyo J, Hyoung Sun Y, San C. Ten years of research change using Google Trends: From the perspective of big data utilizations and applications. Technological Forecasting and Social Change, Elsevier, vol. 130(C), pages 69-87. doi: 10.1016/j.techfore.2017.11.009. URL: https://www.sciencedirect.com/science/article/pii/S0040162517315536

15. Sousa-Pinto B, Anto A, Czarlewski W, Anto JM, Fonseca JA, Bousquet J. Assessment of the Impact of Media Coverage on COVID-19-Related Google Trends Data: Infodemiology Study J Med Internet Res. 2020;22(8):e19611. doi: 10.2196/19611, PMID: 32530816. URL: https://www.jmir.org/2020/8/e19611

16. Centers for Disease Control and Prevention (CDC). Benefits of Getting a COVID-19 Vaccine. 2020, Updated 2021, Apr 12. [Accessed: 2021, Apr 24]. URL: https://www.cdc.gov/coronavirus/2019-ncov/vaccines/vaccine-benefits.html

17. European Medicines Agency (EMA). COVID-19 vaccines: key facts. 2020. [Accessed: 2021, Apr 24]. URL: https://www.ema.europa.eu/en/human-regulatory/overview/public-healththreats/coronavirus-disease-covid-19/treatments-vaccines/vaccines-covid-19/covid-19vaccines-key-facts

18. Rovetta A, Bhagavathula AS. COVID-19-Related Web Search Behaviors and Infodemic Attitudes in Italy: Infodemiological Study JMIR Public Health Surveill 2020;6(2):e19374. doi: 10.2196/19374, PMID: 32338613. URL: https://publichealth.jmir.org/2020/2/e19374

19. Pluchino A, Biondo AE, Giuffrida N, Inturri G, Latora V, Le Moli R, Rapisarda A, Russo G, Zappalà C. A novel methodology for epidemic risk assessment of COVID-19 outbreak. Sci Rep. 2021 Mar 5;11(1):5304. doi: 10.1038/s41598-021-82310-4, PMID: 33674627. URL: https://pubmed.ncbi.nlm.nih.gov/33674627/ 
20. Pegoraro V, Heiman F, Levante A, Urbinati D, Peduto I. An Italian individual-level data study investigating on the association between air pollution exposure and Covid-19 severity in primary-care setting. Preprint under consideration at BMC Public Health. 2021, Feb 26. doi: 10.21203/rs.3.rs-244278/v1. URL: https://www.researchsquare.com/article/rs-244278/v1

21. Auci, S., Vignani, D. Climate variability and agriculture in Italy: a stochastic frontier analysis at the regional level. Econ Polit 37, 381-409 (2020). doi: 10.1007/s40888-020-00172-x. URL: https://doi.org/10.1007/s40888-020-00172-X

22. Rovetta A. Reliability of Google Trends: Analysis of the Limits and Potential of Web Infoveillance During COVID-19 Pandemic and for Future Research. 2020, Dec 29. Preprint on medRxiv, 2020.12.29.20248969. doi: 10.1101/2020.12.29.20248969. URL: https://www.medrxiv.org/content/10.1101/2020.12.29.20248969v1

23. Bufale.net (Italian anti-hoaxes website). The Black List. [Accessed: 2021, Apr 22]. URL: https://www.bufale.net/the-black-list-la-lista-nera-del-web/

24. Alessandrini ER, Faustini A, Chiusolo M, Stafoggia M, Gandini M, Demaria M, et al. Air pollution and mortality in twenty-five Italian cities: results of the EpiAir2 Project. Epidemiol Prev. 2013 Jul-Oct;37(4-5):220-9. PMID: 24293487. URL: https://pubmed.ncbi.nlm.nih.gov/24293487/

25. National Aeronautics and Space Administration (NASA). Global Climate Change - Vital Signs of the Planet. [Accessed: 2021, Apr 24]. URL: https://climate.nasa.gov/effects/

26. European Medicines Agency (EMA). COVID-19 Vaccine Janssen: EMA finds possible link to very rare cases of unusual blood clots with low blood platelets Share. 2021, Apr 20. [Accessed: 2021, Apr 24]. URL: https://www.ema.europa.eu/en/news/covid-19-vaccinejanssen-ema-finds-possible-link-very-rare-cases-unusual-blood-clots-low-blood

27. Rovetta A, Castaldo L. The Impact of COVID-19 on Italian Web Users: A Quantitative Analysis of Regional Hygiene Interest and Emotional Response. 2020, Sep 29. Cureus 12(9): e10719. doi:10.7759/cureus.10719, PMID: $33150116 . \quad$ URL: https://www.cureus.com/articles/41598-the-impact-of-covid-19-on-italian-web-users-aquantitative-analysis-of-regional-hygiene-interest-and-emotional-response

28. BBC News. Coronavirus: YouTube bans 'medically unsubstantiated' content. 2021, Apr 22. [Accessed: 2021, Apr 25]. URL: https://www.bbc.com/news/technology-52388586

29. Twitter. COVID-19 misleading information policy. 2020. [Accessed: 2021, Apr 25]. URL: https://help.twitter.com/en/rules-and-policies/medical-misinformation-policy

30. The Guardian. Facebook bans misinformation about all vaccines after years of controversy. 2021, Feb 8. [Accessed: 2021, Apr 25]. URL: 
https://www.theguardian.com/technology/2021/feb/08/facebook-bans-vaccine$\underline{\text { misinformation }}$

31. Instagram. Keeping People Informed, Safe, and Supported on Instagram. 2020. [Accessed: 2021, Apr 25]. URL: https://about.instagram.com/blog/announcements/coronavirus-keepingpeople-safe-informed-and-supported-on-instagram

32. La Repubblica (Italian national newspaper). Youtube chiude Byoblu. Il fondatore Messora lancia il crowdfunding: "Compriamo un canale sul digitale". 2021, Mar 31. [Accessed: 2021, Apr 25].

URL: https://www.repubblica.it/politica/2021/03/31/news/byoblu_chiusura_youtube_messora294490746/

33. Tagliabue F, Galassi L, Mariani P. The "Pandemic" of Disinformation in COVID-19. SN Compr Clin Med. 2020 Aug 1:1-3. doi: 10.1007/s42399-020-00439-1, PMID: 32838179. URL: https://www.ncbi.nlm.nih.gov/pmc/articles/PMC7395797/

34. Ali S. Combatting Against Covid-19 \& Misinformation: A Systematic Review. Hu Arenas. 2020 Oct 7:1-16. doi: 10.1007/s42087-020-00139-1, PMCID: PMC7538536. URL: https://www.ncbi.nlm.nih.gov/pmc/articles/PMC7538536/

35. Rovetta A, Castaldo L. The influence of mass media on Italian web users during COVID-19: an infodemiological analysis. 2021, Mar 24. Preprint on SocArXiv. doi: 10.31235/osf.io/28m6n. URL: https://doi.org/10.31235/osf.io/28m6n

36. Ferreira GB, Borges S. Media and Misinformation in Times of COVID-19: How People Informed Themselves in the Days Following the Portuguese Declaration of the State of Emergency. Journalism and Media. 2020, Dec 2. 1(1):108-121. doi: 10.3390/journalmedia1010008. URL: https://doi.org/10.3390/journalmedia1010008

37. Fernández-Torres MJ, Almansa-Martínez A, Chamizo-Sánchez R. Infodemic and Fake News in Spain during the COVID-19 Pandemic. International Journal of Environmental Research and Public Health. 2021, Feb 12. 18(4):1781. doi: 10.3390/ijerph18041781. URL: https://doi.org/10.3390/ijerph18041781

38. Today.it (Italian newspaper). "AstraZeneca, paura in Europa": polemiche per il titolo di Repubblica. 2021, Mar 12. [Accessed: 2021, Apr 25]. URL: https://www.today.it/rassegna/vaccino-astrazeneca-oggi-repubblica.html

39. Bufale.net (Italian anti-hoaxes website). I giornali stupiti per i rifiuti al vaccino AstraZeneca dopo giorni di titoloni su reazioni avverse. 2021, Mar 14. [Accessed: 2021, Apr 25]. URL: https://www.bufale.net/i-giornali-stupiti-per-i-rifiuti-al-vaccino-astrazeneca-dopo-giorni-dititoloni-su-reazioni-avverse/ 
40. Bucci E. Chi urla "morto dopo il vaccino!" dovrebbe prima dimostrare il nesso di causalità. Il Foglio (Italian newspaper). 2021, Gen 19. [Accessed: 2021, Apr 25]. URL: https://www.ilfoglio.it/scienza/2021/01/18/news/chi-urla-morto-dopo-il-vaccino-dovrebbeprima-dimostrare-il-nesso-di-causalita--1699059/

41. Elleray E. Public vaccine distrust. Br Dent J. 2021 Jan;230(2):60. doi: 10.1038/s41415-0212617-8. PMID: 33483639. URL: https://www.ncbi.nlm.nih.gov/pmc/articles/PMC7821456/

42. Bogart LM, Ojikutu BO, Tyagi K, Klein DJ, Mutchler MG, Dong L, et al. COVID-19 Related Medical Mistrust, Health Impacts, and Potential Vaccine Hesitancy Among Black Americans Living With HIV. J Acquir Immune Defic Syndr. 2021 Feb 1;86(2):200-207. doi: 10.1097/QAI.0000000000002570, PMID: $33196555 . \quad$ URL: https://pubmed.ncbi.nlm.nih.gov/33196555/

43. Caudal H, Briend-Godet V, Caroff N, Moret L, Navas D, Huon JF. Vaccine distrust: Investigation of the views and attitudes of parents in regard to vaccination of their children. Ann Pharm Fr. 2020 Jul;78(4):294-302. doi: 10.1016/j.pharma.2020.03.003, PMID: 32434681. URL: https://pubmed.ncbi.nlm.nih.gov/32434681/

44. Ecker UK, Lewandowsky S, Chang EP, Pillai R. The effects of subtle misinformation in news headlines. J Exp Psychol Appl. 2014 Dec;20(4):323-35. doi: 10.1037/xap0000028, PMID: 25347407. URL: https://pubmed.ncbi.nlm.nih.gov/25347407/

45. Greinacher A, Thiele T, Warkentin TE, Weisser K, Kyrle PA, Eichinger S. Thrombotic Thrombocytopenia after ChAdOx1 nCov-19 Vaccination. N Engl J Med. 2021 Apr 9. doi: 10.1056/NEJMoa2104840, $33835769 . \quad$ PMID: URL: https://pubmed.ncbi.nlm.nih.gov/33835769/

46. Schultz NH, Sørvoll IH, Michelsen AE, Munthe LA, Lund-Johansen F, Ahlen MT, et al. Thrombosis and Thrombocytopenia after ChAdOx1 nCoV-19 Vaccination. N Engl J Med. 2021 Apr 9. doi: 10.1056/NEJMoa2104882, PMID: 33835768. URL: https://pubmed.ncbi.nlm.nih.gov/33835768/

47. U.S. Food and Drug Administration (FDA). Joint CDC and FDA Statement on Johnson \& Johnson COVID-19 Vaccine. 2021, Apr 13. [Accessed: 2021, Apr 25]. URL: https://www.fda.gov/news-events/press-announcements/joint-cdc-and-fda-statementjohnson-johnson-covid-19-vaccine

48. Manisalidis I, Stavropoulou E, Stavropoulos A, Bezirtzoglou E. Environmental and Health Impacts of Air Pollution: A Review. Front Public Health. 2020 Feb 20;8:14. doi: 10.3389/fpubh.2020.00014, PMID: 32154200 .

URL: https://www.ncbi.nlm.nih.gov/pmc/articles/PMC7044178/

49. Østergaard SD, Schmidt M, Horváth-Puhó E, Thomsen RW, Sørensen HT. Thromboembolism and the Oxford-AstraZeneca COVID-19 vaccine: side-effect or 
coincidence? Lancet. 2021 Apr 17;397(10283):1441-1443. doi: 10.1016/S01406736(21)00762-5, PMID: 33798498. URL: https://pubmed.ncbi.nlm.nih.gov/33798498/

50. Vogel G, Kupferschmidt K. Side effect worry grows for AstraZeneca vaccine. Science. 2021 Apr 2;372(6537):14-15. doi: 10.1126/science.372.6537.14, PMID: 33795437. URL: https://pubmed.ncbi.nlm.nih.gov/33795437/

51. Hunter P R. Thrombosis after covid-19 vaccination BMJ 2021; 373 :n958 doi:10.1136/bmj.n958. URL: https://www.bmj.com/content/373/bmj.n958

52. Muñoz-Rivas N, Abad-Motos A, Mestre-Gómez B, Sierra-Hidalgo F, Cortina-Camarero C, Lorente-Ramos RM, et al. Systemic thrombosis in a large cohort of COVID-19 patients despite thromboprophylaxis: A retrospective study. Thromb Res. 2021 Mar;199:132-142. doi: 10.1016/j.thromres.2020.12.024, PMID: 33503547.

URL: https://pubmed.ncbi.nlm.nih.gov/33503547/

53. Porfidia A, Valeriani E, Pola R, Porreca E, Rutjes AWS, Di Nisio M. Venous thromboembolism in patients with COVID-19: Systematic review and meta-analysis. Thromb Res. 2020 Dec;196:67-74. doi: 10.1016/j.thromres.2020.08.020, PMID: 32853978. URL: https://www.ncbi.nlm.nih.gov/pmc/articles/PMC7420982/ 